\title{
Abdominal tuberculosis: a radiological review with emphasis on computed tomography and magnetic resonance imaging findings"
}

\author{
Tuberculose abdominal: uma revisão radiológica com ênfase em achados de tomografia \\ computadorizada e ressonância magnética
}

\author{
Eduardo Lima da Rocha ${ }^{1}$, Bruno Cheregati Pedrassa ${ }^{1}$, Renata Lilian Bormann ${ }^{1}$, Marcelo Longo \\ Kierszenbaum ${ }^{1}$, Lucas Rios Torres ${ }^{2}$, Giuseppe D'Ippolito ${ }^{3}$
}

Rocha EL, Pedrassa BC, Bormann RL, Kierszenbaum ML, Torres LR, D'lppolito G. Abdominal tuberculosis: a radiological review with emphasis on computed tomography and magnetic resonance imaging findings. Radiol Bras. 2015 Mai/Jun;48(3):181-191.

Abstract Tuberculosis is a disease whose incidence has increased principally as a consequence of HIV infection and use of immunosuppressive drugs. The abdomen is the most common site of extrapulmonary tuberculosis. It may be confused with several different conditions such as inflammatory bowel disease, cancer and other infectious diseases. Delay in the diagnosis may result in significantly increased morbidity, and therefore an early recognition of the condition is essential for proper treatment. In the present essay, cases with confirmed diagnosis of abdominal tuberculosis were assessed by means of computed tomography and magnetic resonance imaging, demonstrating the involvement of different organs and systems, and presentations which frequently lead radiologists to a diagnostic dilemma. A brief literature review was focused on imaging findings and their respective prevalence.

Keywords: Tuberculosis; Abdomen; Computed tomography; Magnetic resonance imaging.

Resu mo A tuberculose é uma doença que vem crescendo, principalmente em consequência da infecção por HIV e do uso de drogas imunossupressoras. $O$ abdome é o foco extrapulmonar mais comum de tuberculose. Pode ser confundida com diversas condições, como doença intestinal inflamatória, neoplasias e outras doenças infecciosas. O retardo no diagnóstico pode resultar em um aumento significativo da morbidade, sendo essencial o seu reconhecimento precoce para o tratamento adequado. Neste estudo avaliamos, por meio de tomografia computadorizada e ressonância magnética, casos com diagnóstico confirmado de tuberculose abdominal, demonstrando o acometimento de diversos órgãos e sistemas, e apresentações que podem levar o radiologista a um dilema diagnóstico. Uma breve revisão da literatura foi realizada enfocando os achados já descritos e a sua prevalência.

Unitermos: Tuberculose; Abdome; Tomografia computadorizada; Ressonância magnética.

\section{INTRODUCTION}

Tuberculosis is responsible for about 1.7 million deaths annually worldwide, and the number of new cases (more than 9 million) is the greatest in history ${ }^{(1)}$. Tuberculosis is known to be associated with poverty, deprivation and immunodeficiency $^{(2)}$.

Lungs are the primary involved organs and abdominal involvement occurs in about $11-12 \%$ of patients with extrapulmonary tuberculosis ${ }^{(3-5)}$. In Brazil, according to recent

* Study developed at Department of Imaging Diagnosis - Escola Paulista de Medicina da Universidade Federal de São Paulo (EPM-Unifesp), São Paulo, SP, Brazil.

1. MDs, Radiologists at Unit of Abdomen, Department of Imaging Diagnosis Escola Paulista de Medicina da Universidade Federal de São Paulo (EPM-Unifesp), São Paulo, SP, Brazil.

2. Fellow, Department of Imaging Diagnosis - Escola Paulista de Medicina da Universidade Federal de São Paulo (EPM-Unifesp), São Paulo, SP, Brazil.

3. Professor at Department of Imaging Diagnosis - Escola Paulista de Medicina da Universidade Federal de São Paulo (EPM-Unifesp), São Paulo, SP, Brazil.

Mailing Address: Dr. Giuseppe D'Ippolito. Departamento de Diagnóstico por Imagem - EPM-Unifesp. Rua Napoleão de Barros, 800, Vila Clementino. São Paulo, SP, Brazil, 04024-012. E-mail: giuseppe_dr@uol.com.br.

Received May 16, 2013. Accepted after revision April 25, 2014. data available at Datasus (www.datasus.gov.br), the tuberculosis incidence rate, including all the disease presentations, in 2010, corresponded to 37.57:100,000 inhabitants, while the incidence rate for the extrapulmonary presentation of the disease was 5.28. In 2010, 71,658 new cases of tuberculosis were recorded in Brazil, as all the disease presentations are considered; and among those cases, 10,071 were extrapulmonary tuberculosis.

The abdominal presentation may involve different structures such as gastrointestinal tract, genitourinary tract, solid organs (liver, spleen, pancreas), gallbladder, aorta and its branches, peritoneum and lymph nodes, frequently with concomitant involvement of those organs ${ }^{(6,7)}$.

The disease may mimic several other conditions such as lymphoma, Crohn's disease, amebiasis, adenocarcinoma, among others. Imaging findings are not pathognomonic, but may be highly suggestive of the disease as considered in conjunction with clinical findings, immunological conditions and the demographic origin of the patient ${ }^{(7)}$.

Abdominal tuberculosis may affect practically any intracavitary organ, presenting quite nonspecific symptoms. In 
a series with 49 patients with abdominal tuberculosis, Sinan et al. ${ }^{(8)}$ stratified in detail the main symptoms and imaging findings. Fever (75\%), abdominal pain (65\%) and weight loss (36\%) had higher prevalence than other signs and symptoms. Peritonitis (38\%) was the main tomographic finding, followed by lymph node disease (23\%), involvement of the gastrointestinal tract (19\%) and solid organs (10\%). Diffuse pattern of lymph node commitment was most commonly observed $(48 \%)$. In the gastrointestinal tract, the terminal ileum and the ileocecal region were most remarkably affected $(50 \%)$. Among the solid organs, liver and spleen presented greater involvement $(70 \%)$.

The present essay is aimed at reviewing and illustrating the main presentations of abdominal tuberculosis by means of images acquired by computed tomography $(\mathrm{CT})$ and magnetic resonance imaging (MRI).

\section{PERITONEUM}

Peritoneal tuberculosis is the most common presentation of abdominal tuberculosis ${ }^{(7,8)}$ and includes the involvement of the peritoneal cavity, mesenterium and omentum ${ }^{(7)}$. It is believed that its origin is hematogenous, but it may be secondary to lymph node rupture, gastrointestinal dissemination or tubal involvement ${ }^{(9)}$. Most probably, it results from rupture of mesenteric lymph nodes compromised by hematogenous dissemination of a distant primary focus (usually located in the lungs). Other accepted dissemination pathways include direct extension and the lymphatic chain. It rarely results from genitourinary tract infection ${ }^{(10)}$.

Despite a certain difficulty in differentiating between the several abdominal tuberculosis presentations, besides a considerable superimposition of presentation patterns, peritoneal tuberculosis is classically classified into three types according to its macroscopic aspects, namely: dry, wet and fibrous types ${ }^{(7,9,11-13)}$. The wet type (Figure 1) presents primarily either as free or loculated ascites, associated or not with diffuse and smooth peritoneal thickening; in the dry type, there is a predominance of peritoneal and mesenteric thickening with caseous nodules, lymph nodes enlargement and fibrinous adhesions; on its turn, the fibrous type (Figure 2) is characterized by remarkable omental thickening and entanglement of bowel loops clinically resembling a mass, occasionally with loculated ascites and that may be similar to peritoneal carcinomatosis ${ }^{(7,14)}$.

Free or loculated ascites may be present in $30-100 \%$ of cases, and the tomographic density is variable (20-45 HU), depending on the phase of the disease. Only $3 \%$ of patients present with the dry-type tuberculous peritonitis. The presence of fat-fluid level in association with necrotic lymph nodes is highly specific for tuberculous ascites ${ }^{(6)}$.

The omentum may be altered in up to $80 \%$ of cases, appearing as diffuse infiltration, nodule, and omental cake. Diffuse densification is most commonly found (Figure 2), while the omental cake pattern, characterized by omental fat thickening and densification, is less frequently seen, occurring in
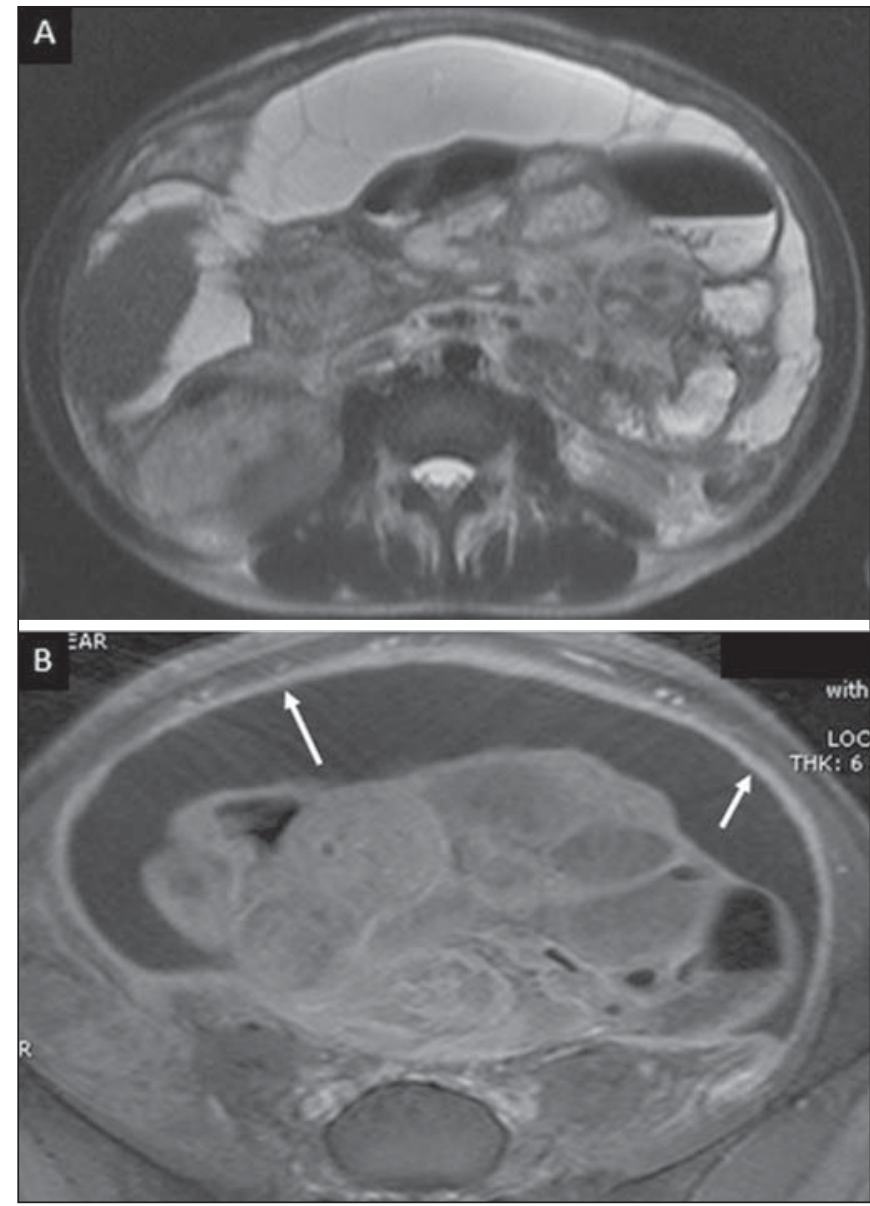

Figure 1. Wet peritonitis in a 27-year-old, female patient. Axial MRI T2-weighted sequence (A) demonstrates large ascites with multiple fine septa. Gadoliniumenhanced MRI T1-weighted image (B) shows diffuse, smooth and regular peritoneal thickening (arrows).

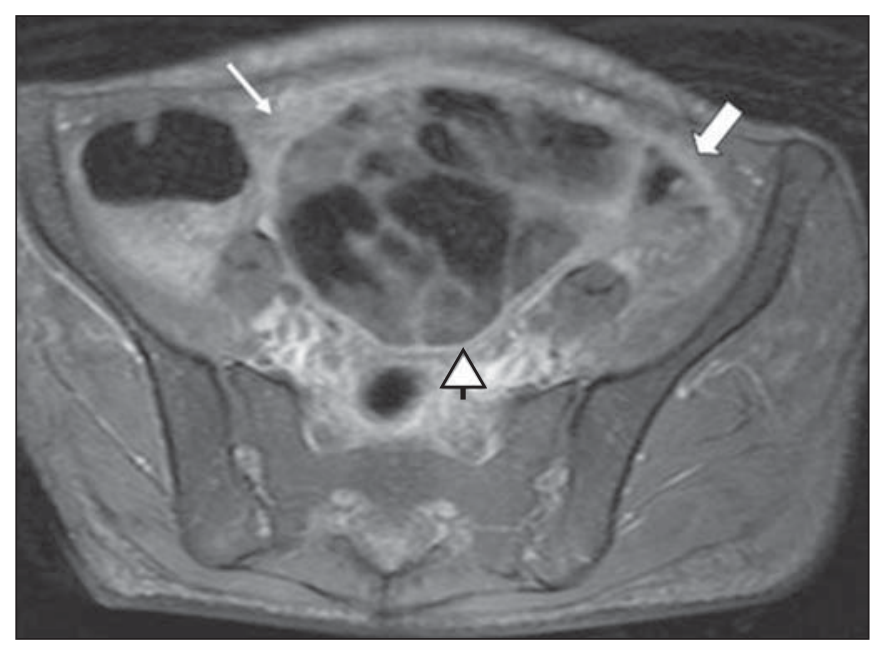

Figure 2. Fibrinous peritonitis. MRI T2-weighted image with fat-suppression showing omental (thin arrow) and diffuse peritoneal (thick arrow) thickening associated with bowel loops conglomerate occupying the pelvic cavity (arrowhead).

$<20 \%$ of cases, but it is most typically found in peritoneal carcinomatosis, in up to $40 \%$ of cases ${ }^{(6,14)}$.

Mesenteric disease is a common abnormality that may be observed at CT as early as at the initial stages of peritoneal tuberculosis, in up to $98 \%$ of cases $^{(14)}$, ranging from a 
mild involvement (linear striations, vascular engorgement, star-shaped appearance, fat densification) to a more extensive involvement (diffuse infiltration of the mesenteric leaves). Mesenteric abscesses probably result from extension of a caseous process of large lymph node masses ${ }^{(13)}$. Thick striations with vascular engorgement constitute the most common finding (65\% of cases), followed by the nodular pattern $(29 \%)^{(14)}$.

The diagnosis of peritoneal tuberculosis remains as a challenge due to the wide range of clinical presentations, nonspecific laboratory findings and superimposition of imaging findings with other diseases, particularly with peritoneal carcinomatosis, whose treatment and prognosis are completely different. Thus, the most common CT findings in peritoneal tuberculosis include: a) ascites (70-90\% of cases); b) smooth peritoneal thickening with marked enhancement after intravenous contrast injection; c) densification of the mesenteric root fat planes, which may occur in up $70 \%$ of cases; d) lymph node enlargement with areas of central necrosis or calcification $^{(6,14,15)}$.

On the other hand, the most frequent findings in peritoneal carcinomatosis include: a) multinodular and irregular peritoneal thickening; b) homogeneous retroperitoneal lymph nodes enlargement; c) omental cake, as above mentioned $^{(6,15)}$.

The most useful tomographic sign to differentiate between peritoneal tuberculosis and peritoneal carcinomatosis is peritoneal thickening that, in the first condition, is smooth and regular, and in the second, is nodular and irregular $^{(6)}$.

Nontuberculous peritonitis (bacterial peritonitis, for example), peritoneal pseudomyxoma and mesothelioma constitute the spectrum of the main differential diagnoses of peritoneal tuberculosis $^{(9,11,12,15)}$.

\section{LYMPH NODES}

Lymph node involvement is usually associated with gastrointestinal tuberculosis and less commonly with the peritoneal and solid organs presentations, but it may be the only sign of disease, particularly in the periportal region ${ }^{(16)}$. The most common involvement of lymph node chains (mesenteric, celiac, porta hepatis, and peripancreatic lymph nodes) may be explained by the lymphatic drainage of the ileocecal, jejunal, ileal and right colonic regions after ingestion of infected material $^{(16)}$.

The lymph node disease pattern is variable at CT, most frequently demonstrating lymph node enlargement (40-60\%) with hypoattenuation in the center and hyperattenuation in the periphery, after intravenous contrast injection, which is typical but not pathognomonic of caseous necrosis (Figure $3)^{(9)}$. Lymphoma, metastasis, pyogenic infection and Whipple's disease are the main differential diagnoses ${ }^{(11,16)}$. Other lymph node involvement patterns include increase in the number but not in volume of lymph nodes, large, localized lymph nodes clusters and conglomerates (Figure 4) ${ }^{(16)}$.
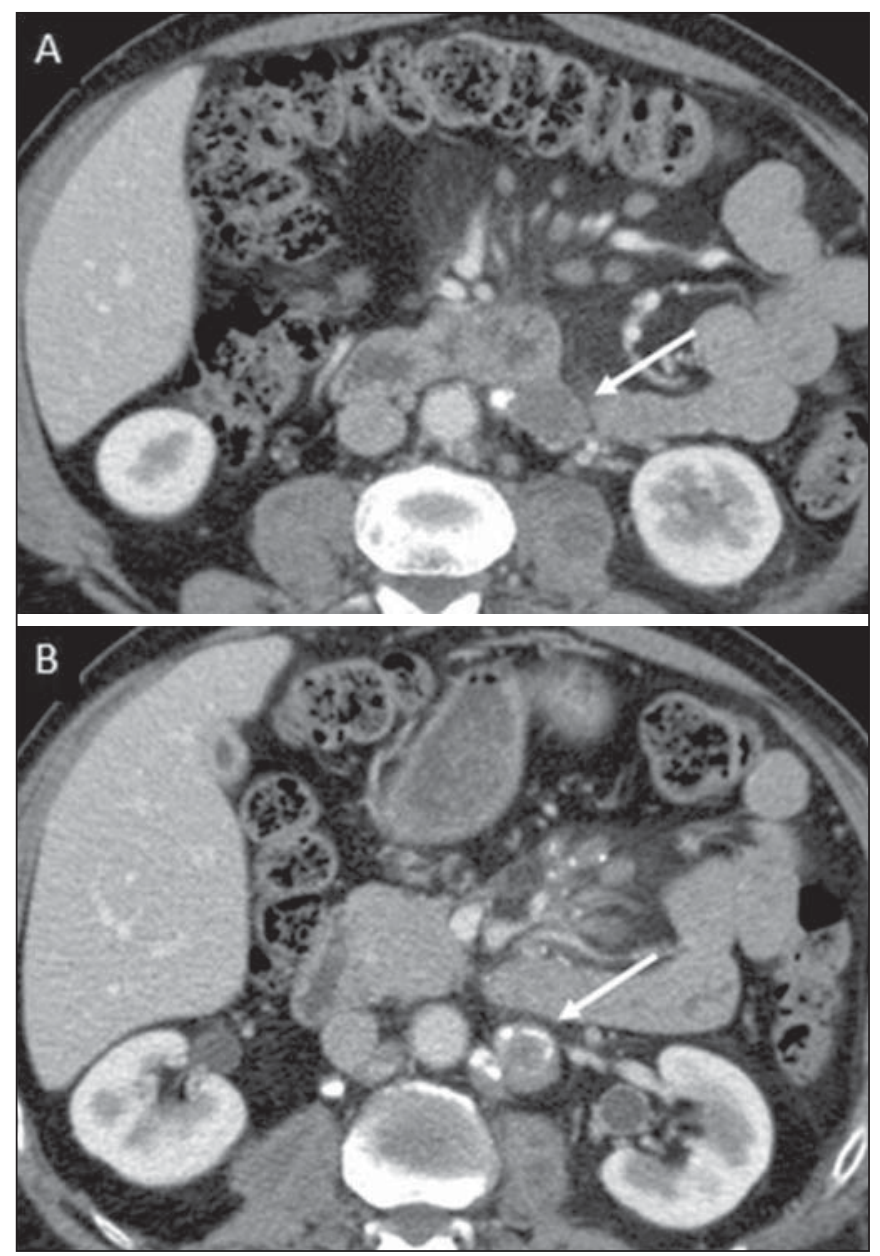

Figure 3. Tuberculous lymph node disease in a 54-year-old, male patient. Presence of multiple enlarged lymph nodes in the mesenteric root and periaortic region. Enlarged lymph node with central necrosis (arrow on A). Also, gross lymph node calcifications are observed (arrow on $\mathbf{B}$ ).

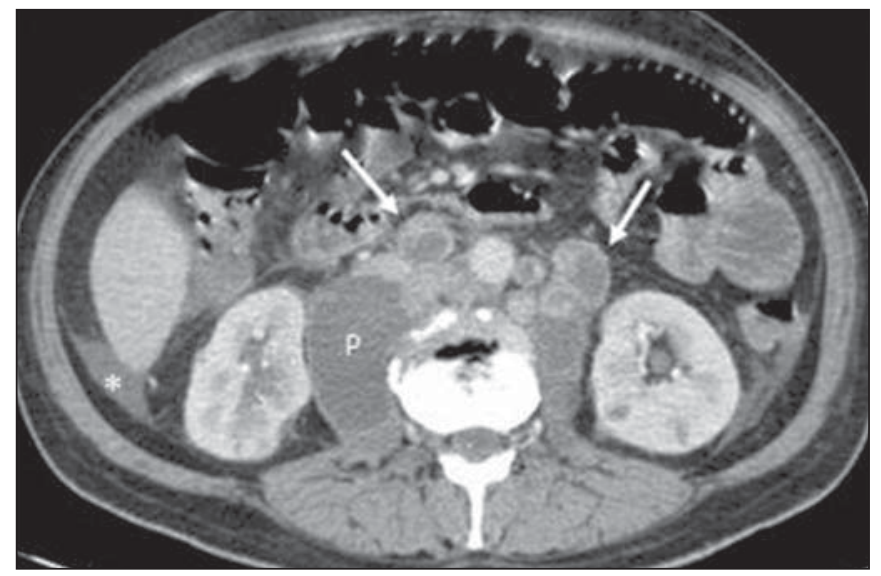

Figure 4. Tuberculous lymph node disease in a 55-year-old, male patient. Multiple enlarged lymph nodes (arrows) with central necrosis in periaortic, pericaval and interaortocaval chains. Large tuberculous abscesses in both psoas muscles (P) and small amount of ascites (asterisk) are observed.

\section{GASTROINTESTINAL TRACT}

The intestinal presentation of abdominal tuberculosis is not uncommon ${ }^{(16)}$. Some mechanisms may lead to bowel involvement by the disease: ingestion of infected material in 
active pulmonary tuberculosis; reactivation of a quiescent intestinal focus resulting from hematogenous dissemination in the childhood, hematogenous dissemination of active tuberculosis, or direct spread from other organs ${ }^{(17)}$.

Tuberculosis may involve any gastrointestinal tract segment, but there is a preponderance in the ileocecal valve, terminal ileum and cecum ${ }^{(7,12,16,18)}$, which occurs in up to $90 \%$ of intestinal tuberculosis cases (Figure $5 \mathrm{~A})^{(9,12,16)}$.

Main imaging findings of intestinal tuberculosis include symmetrical or asymmetrical parietal thickening, extrinsic compression by enlarged lymph nodes which, on their turn may represent heterogeneous masses as associated with adherent loops and mesenteric thickening ${ }^{(16)}$.

The clinical presentation of rectal tuberculosis is rarer and different from tuberculosis in proximal segments. Hematochezia (88\%) and constipation (37\%) are the most common symptoms. Luminal narrowing is usually significant, with variable length, areas of deep ulceration, most commonly located about $10 \mathrm{~cm}$ from the anal border (Figure 5B). Prominent fibrosis associated with rectal inflammation may increase the presacral space ${ }^{(19)}$. A study published by Nagi et al. ${ }^{(18)}$ revealed an incidence of $10.8 \%$ of colorectal
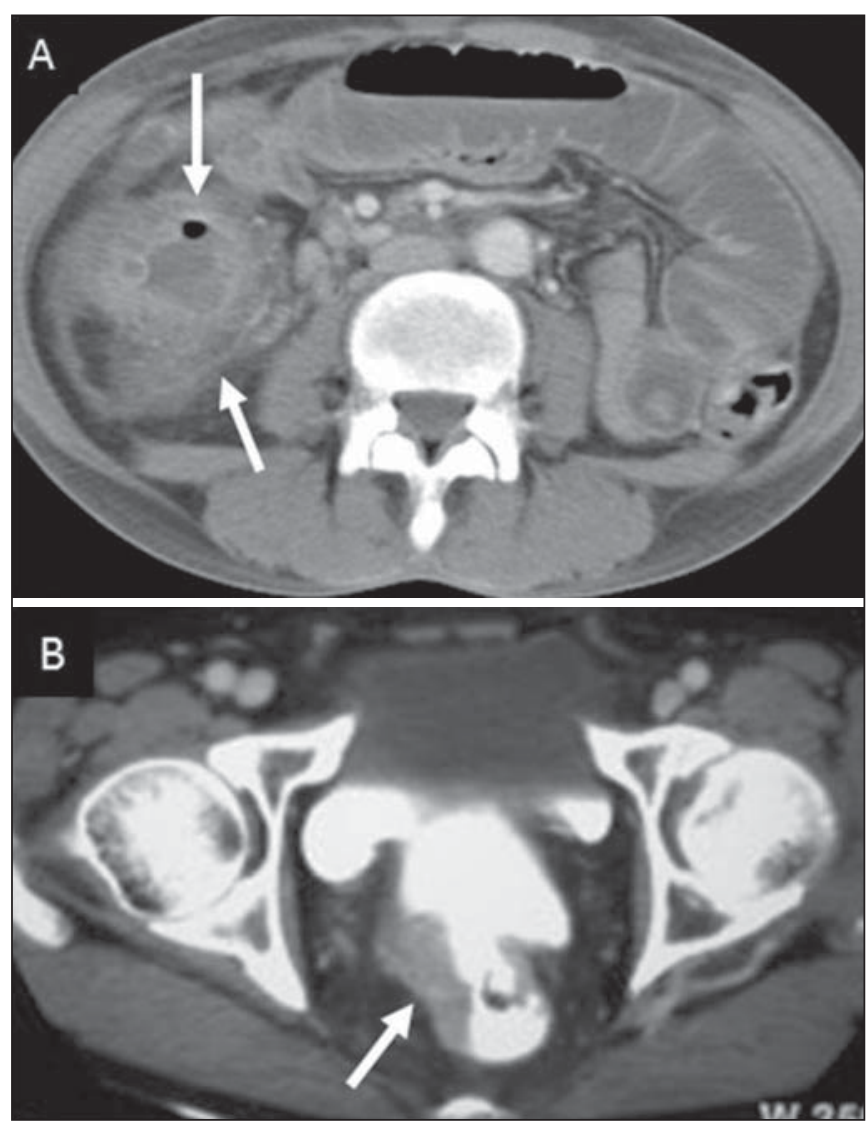

Figure 5. A: Tuberculosis of the cecum and ascending colon. Note the marked, irregular parietal thickening, decreased luminal diameter and densification of adjacent fat planes at the level of the cecum, segment most frequently affected by tuberculosis, adjacent to the region of the ileocecal valve and ascending colon. B: Rectal tuberculosis in another patient. CT image demonstrates irregular, focal thickening, decreased luminal diameter and densification of adjacent fat planes at the level of the rectum, a segment that is rarely affected by tuberculosis. This lesion resembles neoplastic involvement. involvement in a series of 684 patients affected by gastrointestinal tuberculosis along 10 years, in spite of large, previously published series revealing an incidence between $3 \%$ and $9 \%$, with scarce reports about cases of single rectal involvement $^{(18)}$.

Perforation (Figure 6) and fistulas are the most frequent gastrointestinal complications of tuberculosis, with incidence of $7.6 \%$; the small bowel and the colon are the most common sites ${ }^{(20)}$. Other complications include vascular complications, intussusception and obstruction of the small bowel $^{(7)}$.

The differential diagnosis for intestinal tuberculosis varies with the involvement degree and pattern, and includes Crohn's disease, lymphoma, amebiasis and adenocarcinoma. The presence of pulmonary compromise at chest radiography may help in the diagnostic rationale in spite of the fact that it is absent in up $50-60 \%$ of cases $^{(7,16)}$.

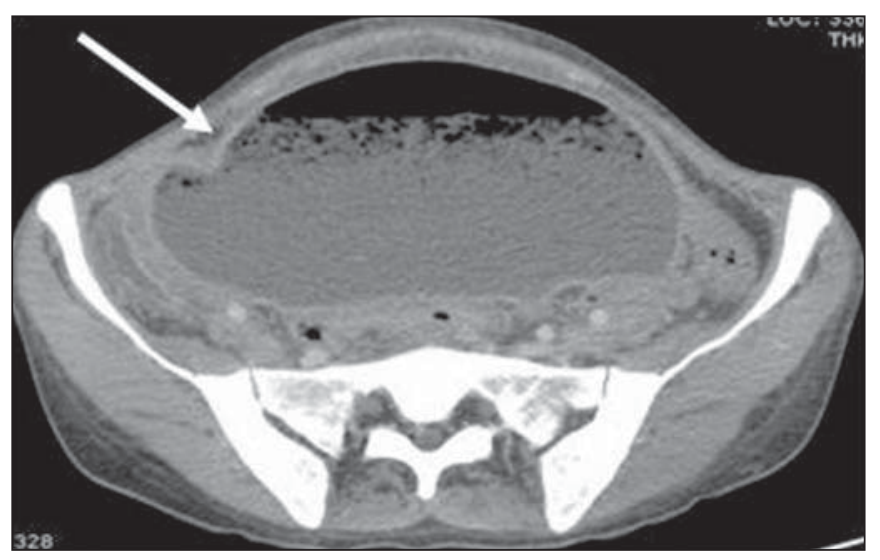

Figure 6. Female, 25-year-old patient presenting intestinal perforation secondary to intestinal tuberculosis, producing a large fluid collection (arrow).

\section{LIVER AND BILIARY TRACT}

Isolated hepatic tuberculosis is a rare condition and is usually associated with concomitant involvement of other organs ${ }^{(21)}$. On the other hand, the prevalence of hepatic commitment in autopsies of patients with disseminated tuberculosis is of $80-100 \%{ }^{(16,21)}$.

Manifestations of hepatic tuberculosis may be divided into two types, namely, miliary and macronodular. The miliary form (Figure 7) is associated with hematogenous dissemination, and hence the diffuse involvement of the liver ${ }^{(4,21)}$. There is a diffuse enlargement of the liver and, despite the increase in hepatic enzyme levels, biliary dilatation may not be noticeable due to the predominance of smallcaliber ducts involvement ${ }^{(21)}$. Most commonly it is related to miliary pulmonary tuberculosis ${ }^{(4,21)}$.

The macronodular presentation (Figure 8) is rarer, less frequently associated with the pulmonary form of tuberculosis and it is related to dissemination through the portal vein $^{(4,21)}$. Calcifications may arise in the chronic phase of the disease $^{(7,9,16)}$. At CT, lesions measuring between 1 and $3 \mathrm{~cm}$ in diameter or single mass may be observed in a diffusely 


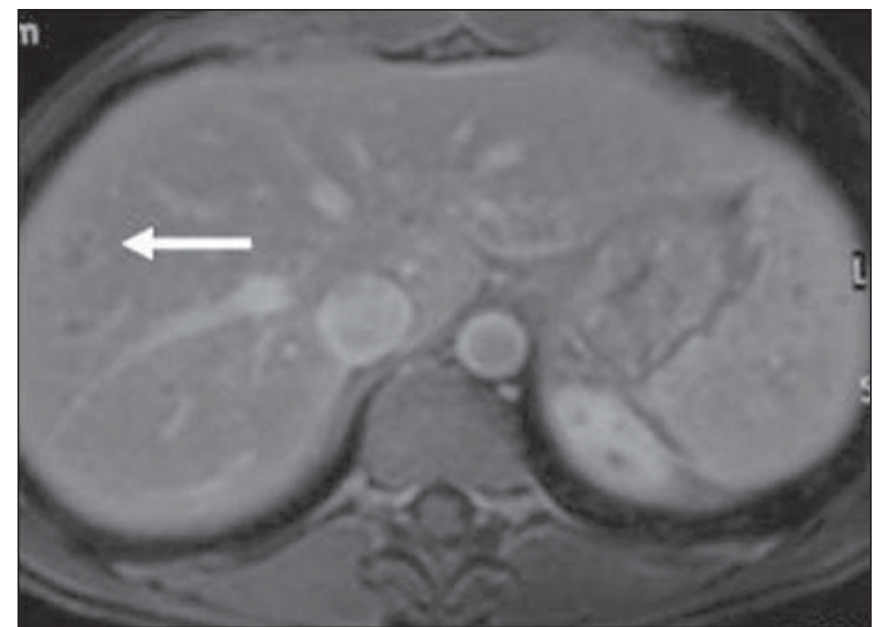

Figure 7. Miliary hepatic tuberculosis. Gadolinium-enhanced, axial MRI, T1weighted image with fat-suppression identifies multiple and small hypovascular nodules that could not be detected at follow-up examination after pertinent therapy.

enlarged liver. At MRI, the lesions present low signal intensity and minimal peripheral enhancement, with a honeycombing pattern in the miliary form at T1-weighted sequences (Figure 7). At T2-weighted sequences, the lesions are hypointense, with a less hypointense halo in relation to the surrounding liver parenchyma ${ }^{(12)}$.

The differential diagnosis for the micronodular form of hepatic tuberculosis includes metastasis, fungal infection, sarcoidosis and lymphoma ${ }^{(12)}$; and in the macronodular form, it is made primarily with abscess and metastasis ${ }^{(12,16,21)}$.

The involvement of the biliary tree by tuberculosis is even more rarely observed and its annual incidence is estimated to be $0.1 \%{ }^{(22)}$. The involvement may be either primary, with small ducts stenosis, or secondary to compression by hepatic granulomas, many times making it more difficult to differentiate with primary sclerosing cholangitis and cholangiocarcinoma ${ }^{(21)}$.

The gallbladder is very rarely involved. Mural thickening, irregular septa, and lymphadenopathy may be found. There is no typical presentation, and it may be quite variable $^{(23)}$. The diagnosis is usually made on the basis of histopathology ${ }^{(7)}$.

\section{SPLEEN}

Splenic tuberculosis is usually associated with the disseminated form of miliary tuberculosis and, in spite of being reported in up to $80-100 \%$ of autopsies of patients with disseminated tuberculosis, it is much less frequently identified by imaging methods ${ }^{(24)}$. However, a recent series reported a rate of splenic involvement diagnosed by imaging methods (ultrasonography, CT or MRI) of $45.8 \%$ in cases of disseminated tuberculosis ${ }^{(24)}$.

As well as hepatic tuberculosis, there are two types of presentations of splenic tuberculosis, namely, miliary and macronodular. The first and most common type (Figure 9A) usually manifests as moderate splenomegaly, but minute hypodense lesions may be seen at CT. The macronodular
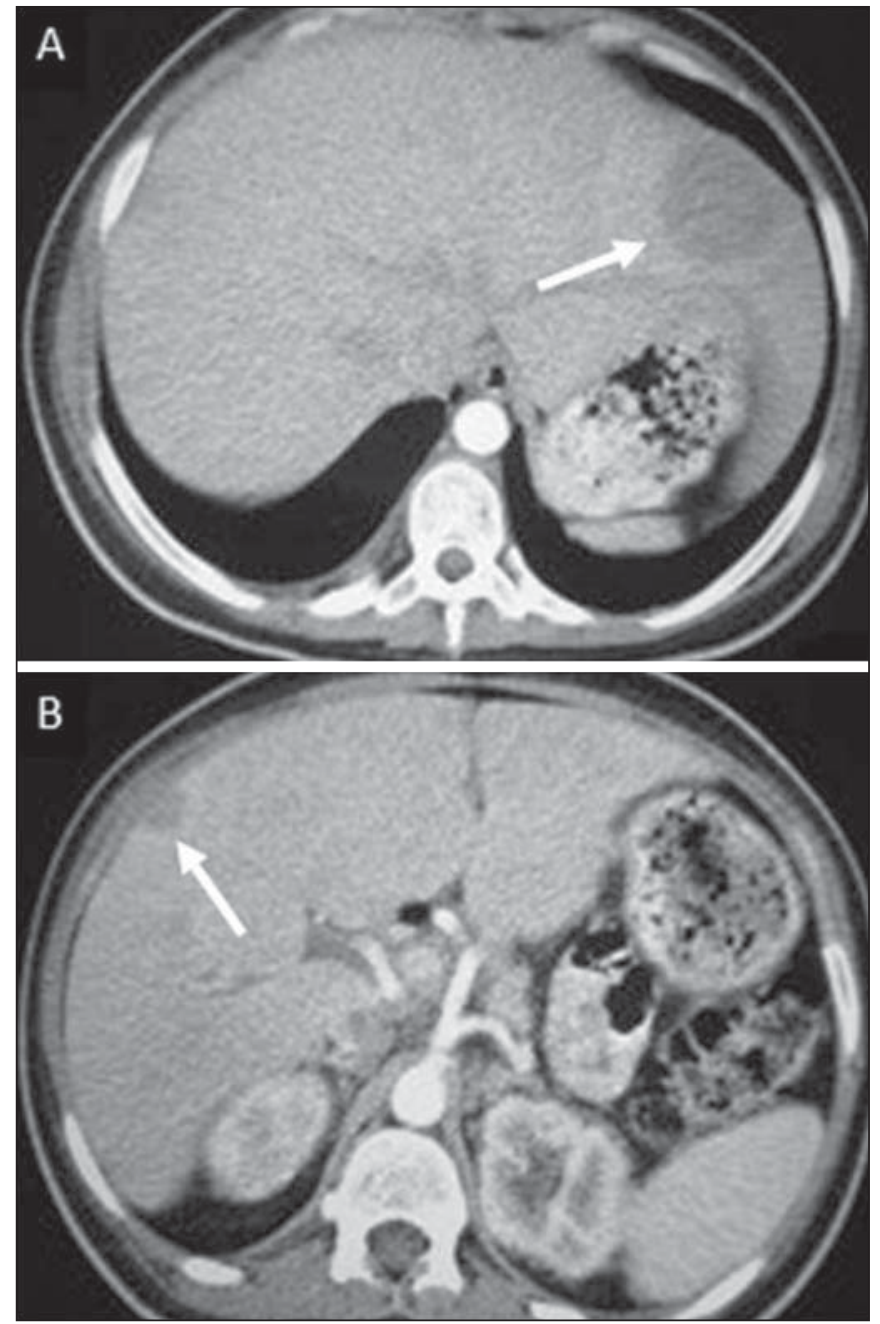

Figure 8. Macronodular hepatic tuberculosis. Contrast-enhanced abdominal CT demonstrating the presence of hypovascular nodules in the left (A) and right (B) lobes.

form (Figure 9B) is extremely rare and is seen either as multiple or solitary, rounded or ovoid nodules with variable appearance both at CT and MRI, which may represent different disease stages. At contrast-enhanced T1-weighted sequences, one can observe peripheral enhancement or, less commonly, gradual and progressive enhancement ${ }^{(24)}$.

The differential diagnosis for multiple focal splenic lesions includes lymphoma, Kaposi's sarcoma, metastasis, sarcoidosis, bacillary angiomatosis, pyogenic/fungal abscesses, histoplasmosis and disseminated Mycobaterium aviumintracellulare and Pneumocystis carini infection ${ }^{(9,16,24)}$.

\section{PANCREAS}

In spite of the fact that pancreatic compromise by tuberculosis is rarely identified at imaging studies, at least one series has reported a prevalence of $8.3 \%$ of pancreatic involvement in 384 patients with diagnosis of abdominal tuberculosis. The described alterations include increased pancreas dimensions (Figure 10), hypodense intrapancreatic collections or complex masses, besides peripancreatic lymphadenopathy ${ }^{(25)}$. 

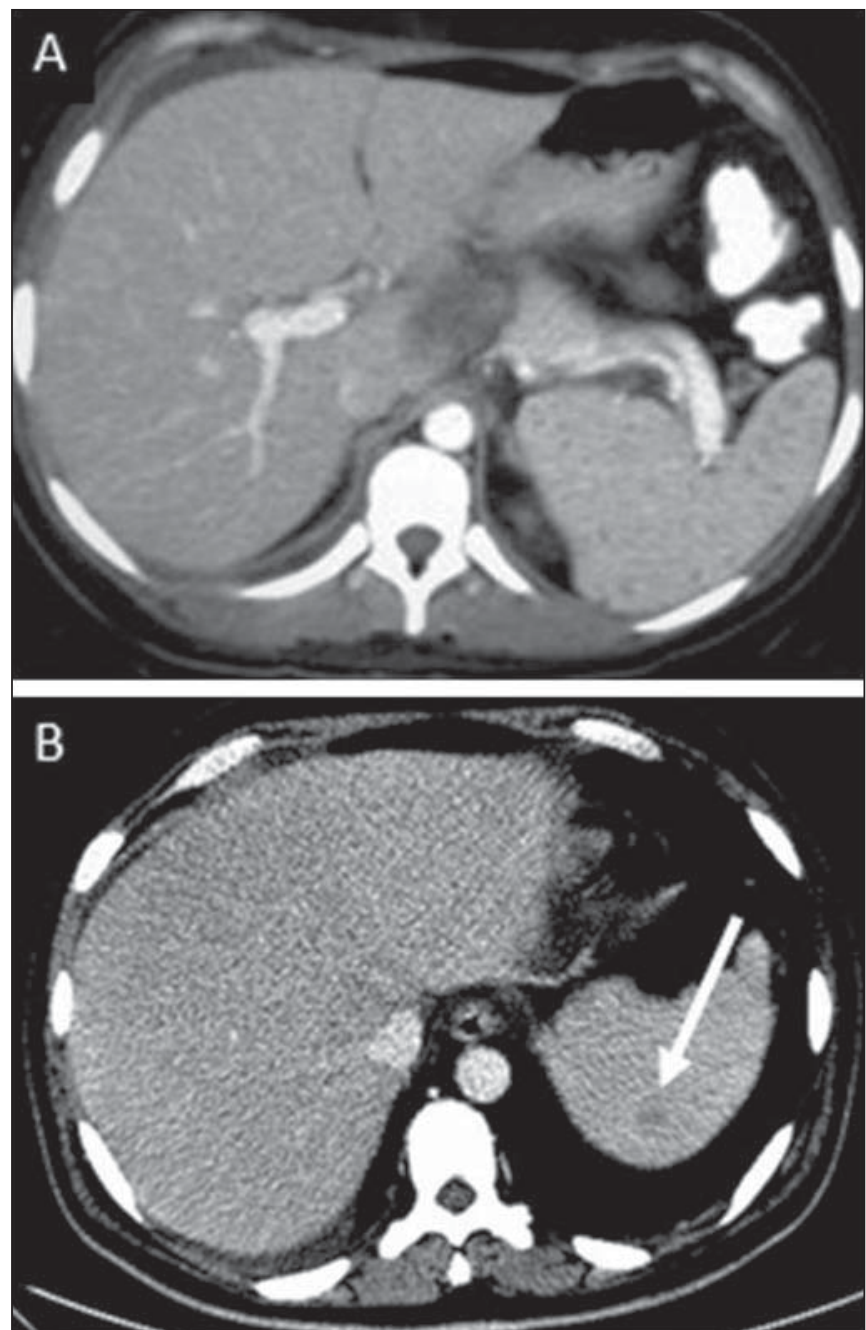

Figure 9. A: Miliary splenic tuberculosis. Contrast-enhanced CT showing minute hypoattenuating, nodules randomly distributed in the spleen. B: Macronodular splenic tuberculosis. Contrast-enhanced CT reveals a single, peripheral nodule in the spleen.

\section{SUPRARENAL GLANDS}

Suprarenal glands are not a rare site of involvement by tuberculosis ${ }^{(26)}$, and this is the main cause of suprarenal gland failure (Addison's disease) $)^{(26)}$.

Suprarenal tuberculosis manifests with increase in gland dimensions (Figure 11A), central necrosis and either unilateral or bilateral calcifications (Figure 11B $)^{(11,12,26)}$. Suprarenal glands enlargement is also observed in patients with renal tuberculosis ${ }^{(11)}$. Atrophy and calcifications may be seen in previously treated patients ${ }^{(11,26)}$.

The radiological differential diagnosis includes metastasis, lymphoma, primary neoplasm, blastomycosis ${ }^{(27)}$ and hemorrhage ${ }^{(26)}$.

\section{KIDNEYS}

In spite of the fact that renal tuberculosis is usually a result of hematogenous dissemination originating from the lungs, less than $50 \%$ of patients present with radiological evidences of pulmonary tuberculosis and only $10 \%$ present with active disease $^{(28)}$. Renal tuberculosis is usually a consequence

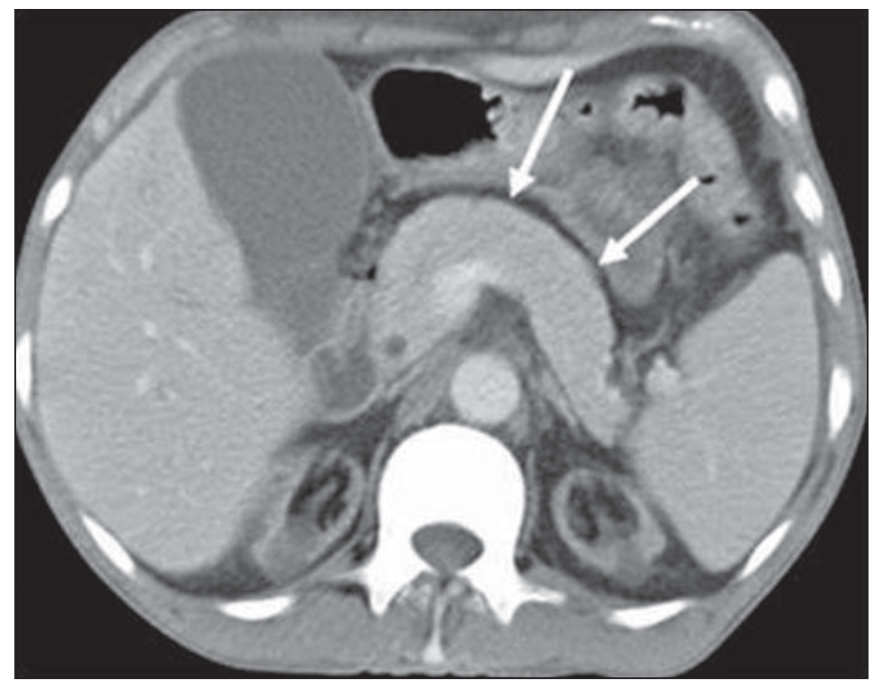

Figure 10. Pancreatic tuberculosis. CT identifies a slight increase in the dimensions of the organ and loss of the habitual, lobulated contours of the pancreas.
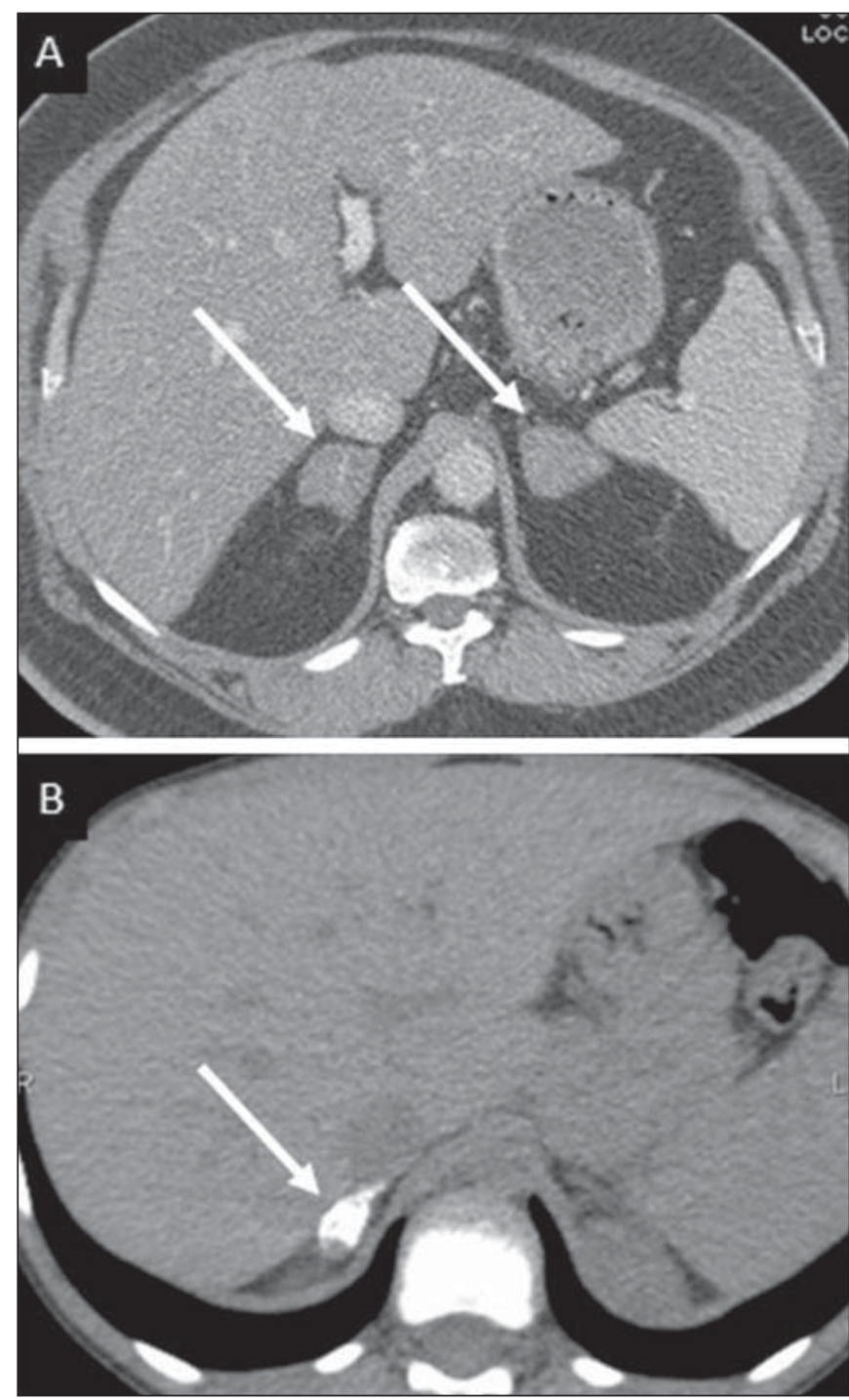

Figure 11. Adrenal tuberculosis. A: CT shows hyperplasia of both adrenal glands. B: In another patient, the right adrenal gland is calcified, exemplifying the chronic phase of the disease. (This image was kindly provided by Prof. Dr. Valdair Muglia - Faculdade de Medicina de Ribeirão Preto da Universidade de São Paulo). 
from a primary pulmonary infection that might have occurred several years before. Tubercle bacilli lodge at the corticomedullary junction, forming granulomas in the papilla which remain stable for many years; if reactivation occurs, the organisms spread into the medulla, causing papillitis ${ }^{(28)}$.

Focal tissue edema and vasoconstriction caused by active inflammation result in local hypoperfusion identifiable at CT and $\mathrm{MRI}^{(26)}$. Calyceal deformity is the initial finding $^{(28)}$. Multiple or solitary parenchymal nodules (Figure 12) with no urinary tract involvement are rare manifestations and may mimic neoplasms ${ }^{(26)}$.

The most characteristic imaging finding is caliectasis (Figures 13 and 14) ${ }^{(11,26)}$.

The disease progression might result in extensive papillary necrosis, cavitation and later cortical scars, pyeloinfundibular strictures and hydronephrosis. At a terminal stage of the disease, lost of renal function and calcifications are observed $^{(28)}$. Calcifications may present with several patterns such as amorphous, granular, lobar and diffuse (named autonephrectomy $)^{(28)}$.

\section{URETERS}

Dilatation and irregular thickening of the urothelium (Figure 15) represent the first signs of ureteral tuberculosis. The dilatation results primarily from ureterovesical junction stricture secondary to cystitis and tuberculous urethritis.

At advanced stages of the disease, ureteral stenosis, shortening, filling defects and ureteral calcifications may be seen (Figure 16) $^{(12)}$.

\section{BLADDER}

Initially, tuberculous cystitis produces mucosal ulceration and edema. The disease extension towards the muscle layer leads to fibrosis and, consequently, to mural thickening and decrease in contractility. For this reason, the main sign of tuberculous cystitis is a thickened bladder and reduced
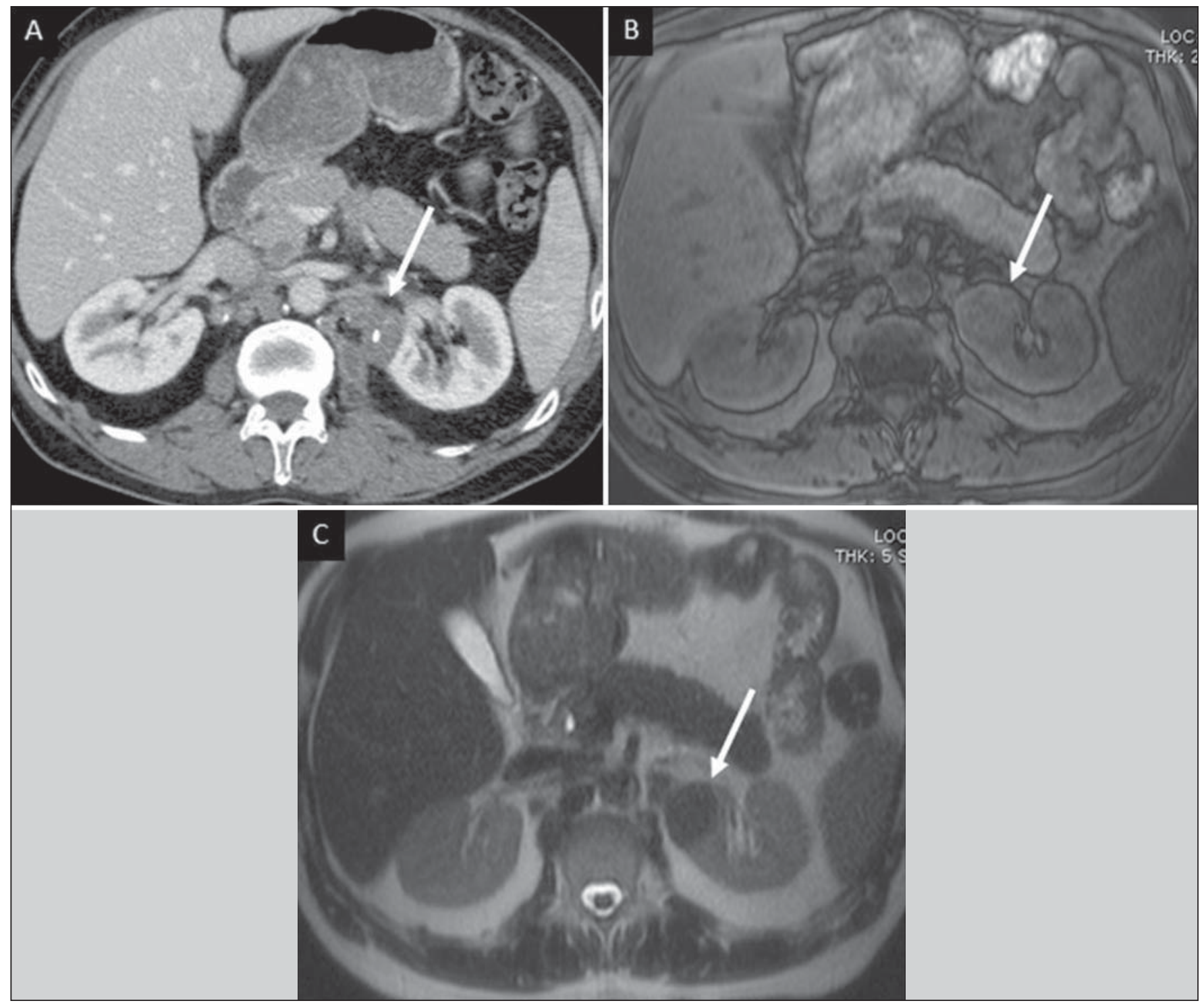

Figure 12. Tuberculoma in left kidney. CT shows hypovascular, partially calcified nodule (A). At MRI, the nodule presents intermediate signal on T1-weighted sequences (B) and low signal intensity on T2-weighted sequences (C). 

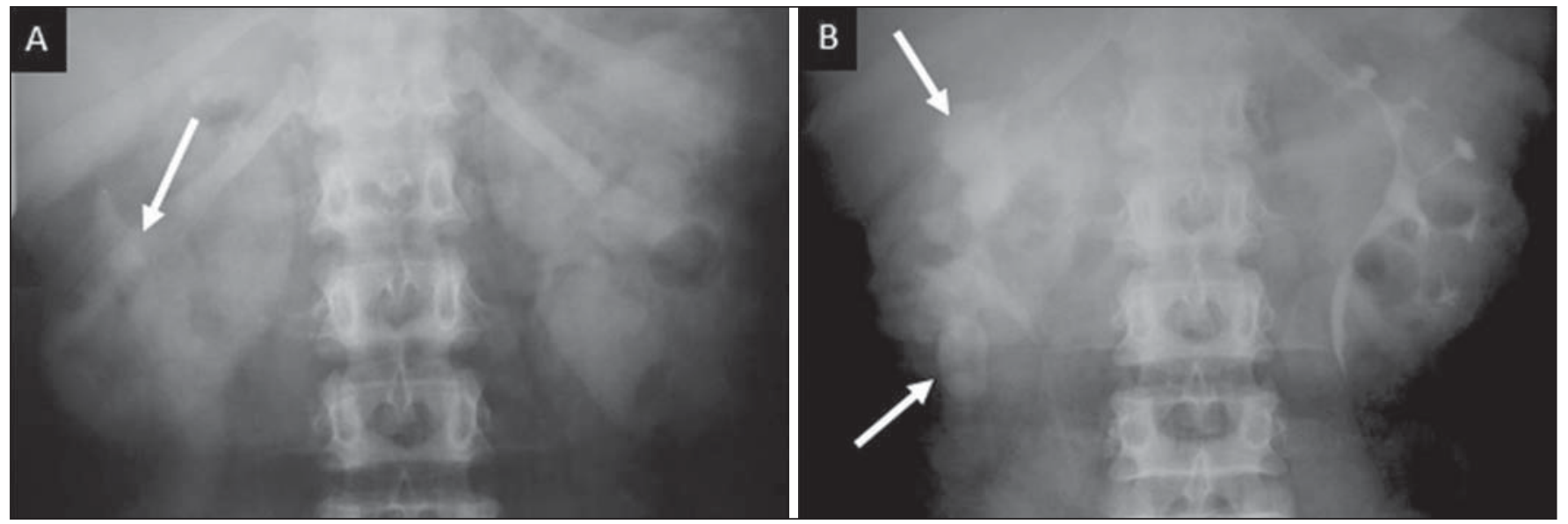

Figure 13. Renal tuberculosis at right. Plain radiography demonstrates spotted calcifications (arrow on A). Excretory urography shows deformity of the pyelocalyceal system, decreased thickness of the renal parenchyma and cavitations filled with contrast agent in contiguity with the renal infundibulum (arrows on B).
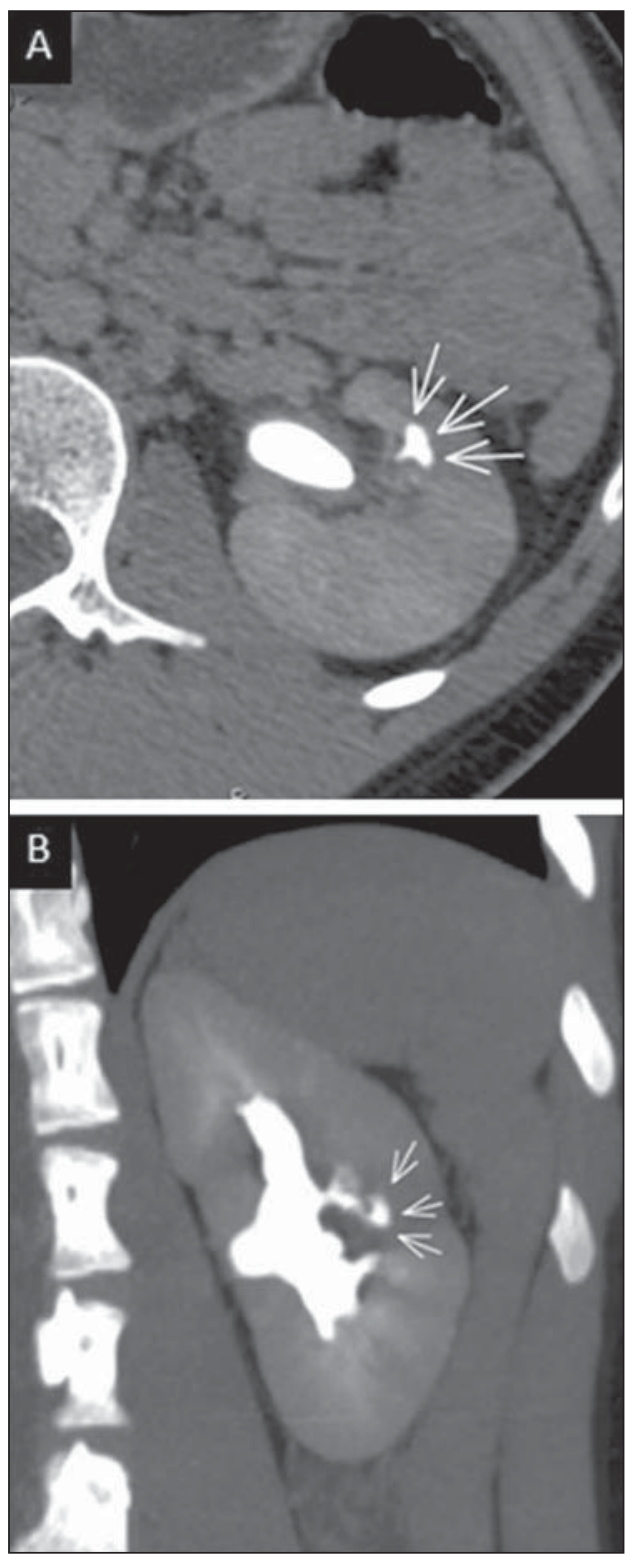

Figure 14. Left renal tuberculosis evolving with calicectasis. Axial CT images $(\mathbf{A})$ and coronal reconstruction (B) demonstrate calicectasis in middle calyceal group at excretory phase (arrows on $\mathbf{A}$ and $\mathbf{B})$.
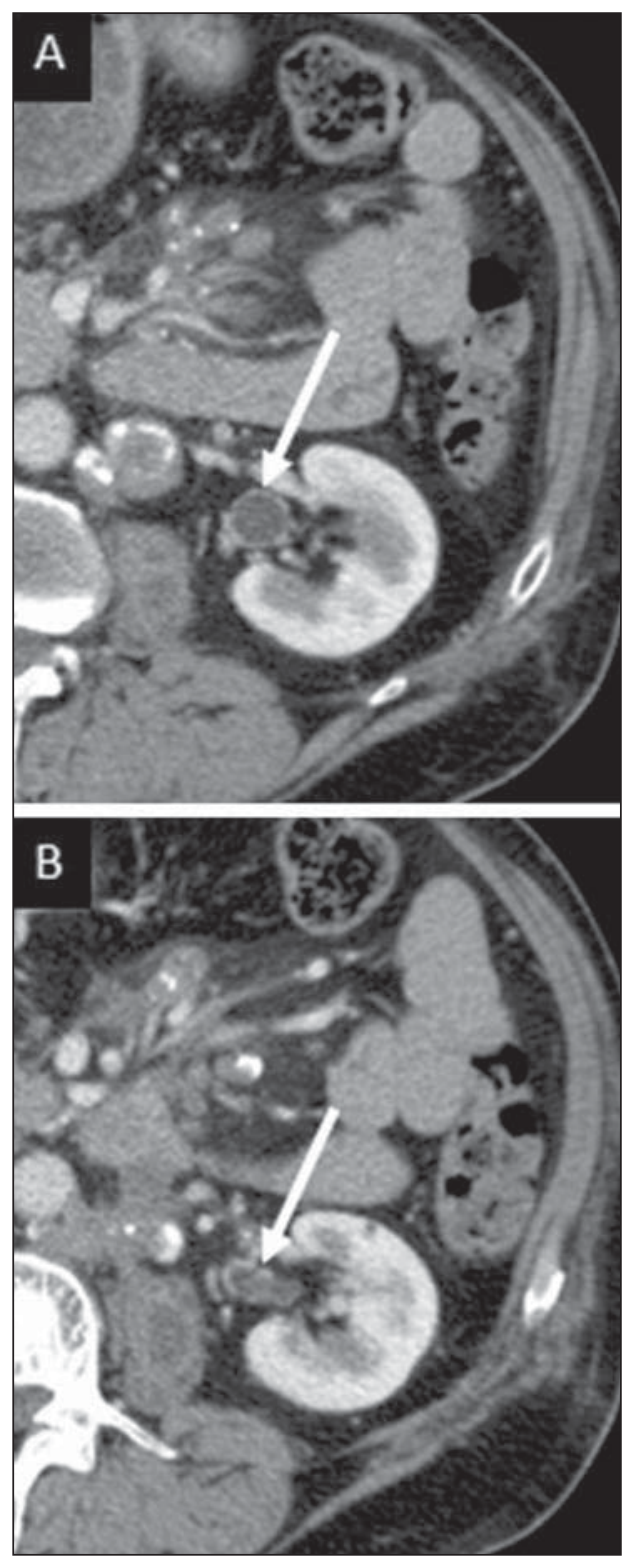

Figure 15. Ureteral tuberculosis. Presence of irregular thickening of the urothelium in the renal pelvis (arrow on $\mathbf{A}$ ) and in the proximal ureter (arrow on $\mathbf{B}$ ). 
bladder capacity (Figures 16 and 17). Ureteral reflux may be observed. Calcified tuberculous cystitis is rare and should be differentiated from other conditions such as schistosomiasis, amyloidosis, cyclophosphamide-induced actinic cystitis, carcinoma and foreign bodies ${ }^{(28)}$.

\section{FEMALE GENITAL ORGANS}

Tuberculous infection of the female genital system may cause menstrual disorders, gestational complications, neonatal tuberculosis, antituberculosis drugs side effects during pregnancy, increased drug-resistance and infertility ${ }^{(29)}$. Chavhan et al. have published a study showing $7.5 \%$ incidence of female genital tuberculosis in 492 patients undergoing

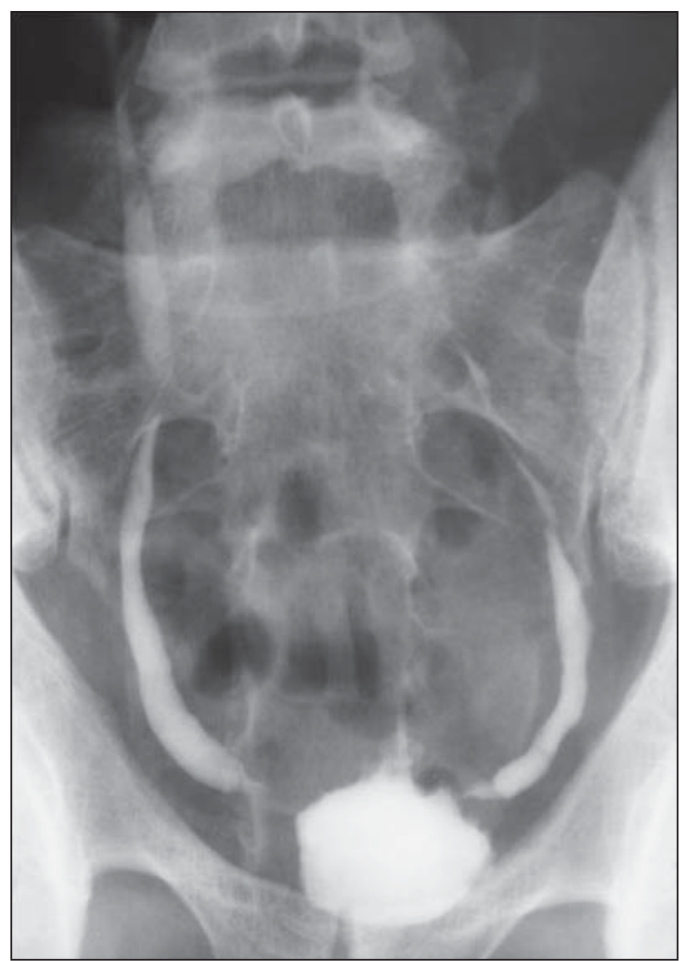

Figure 16. Bilateral ureteral tuberculosis and involvement of the bladder. At excretory urography, irregular distal ureteral stenoses are observed in association decreased capacity and trabecular contour or the bladder.

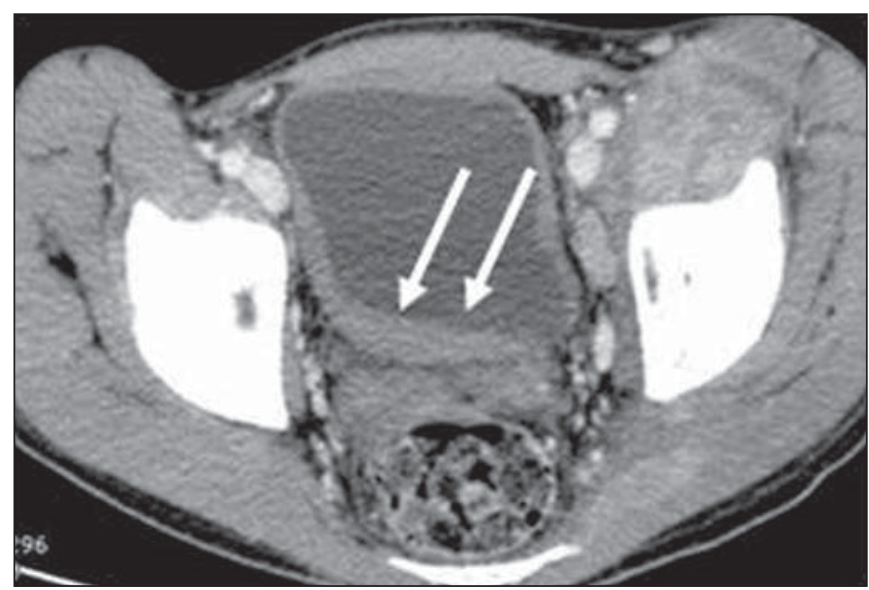

Figure 17. Vesical tuberculosis. CT identifies diffuse and asymmetrical thickening of the vesical wall (arrows). investigation for infertility and submitted to hysterosalpingography $^{(30)}$.

Most women with genital tuberculosis present with infertility secondary to tubal involvement (Figure 18A), which occurs in up to $94 \%$ of such patients. Typically, it is bilateral and causes multifocal stricture and calcifications ${ }^{(12)}$. Tubo-ovarian abscess extending through the peritoneum and extraperitoneal compartment is also suggestive of tubercu$\operatorname{losis}^{(12)}$.

Endometrial tuberculosis occurs in up to $50 \%$ os patients with tubal tuberculosis ${ }^{(26)}$. Tuberculous endometritis may mimic relevant uterine adhesions and endometrial carcinoma (Figure 18B $)^{(11)}$.

\section{MALE GENITAL ORGANS}

Tuberculosis may affect the whole male genital tract, with lesions in the prostate, seminal vesicles, deferent ducts, epididymis, penis and testes. Genital tuberculosis occurs by hematogenous dissemination to the prostate and epididymides or through the urinary system to the prostate with
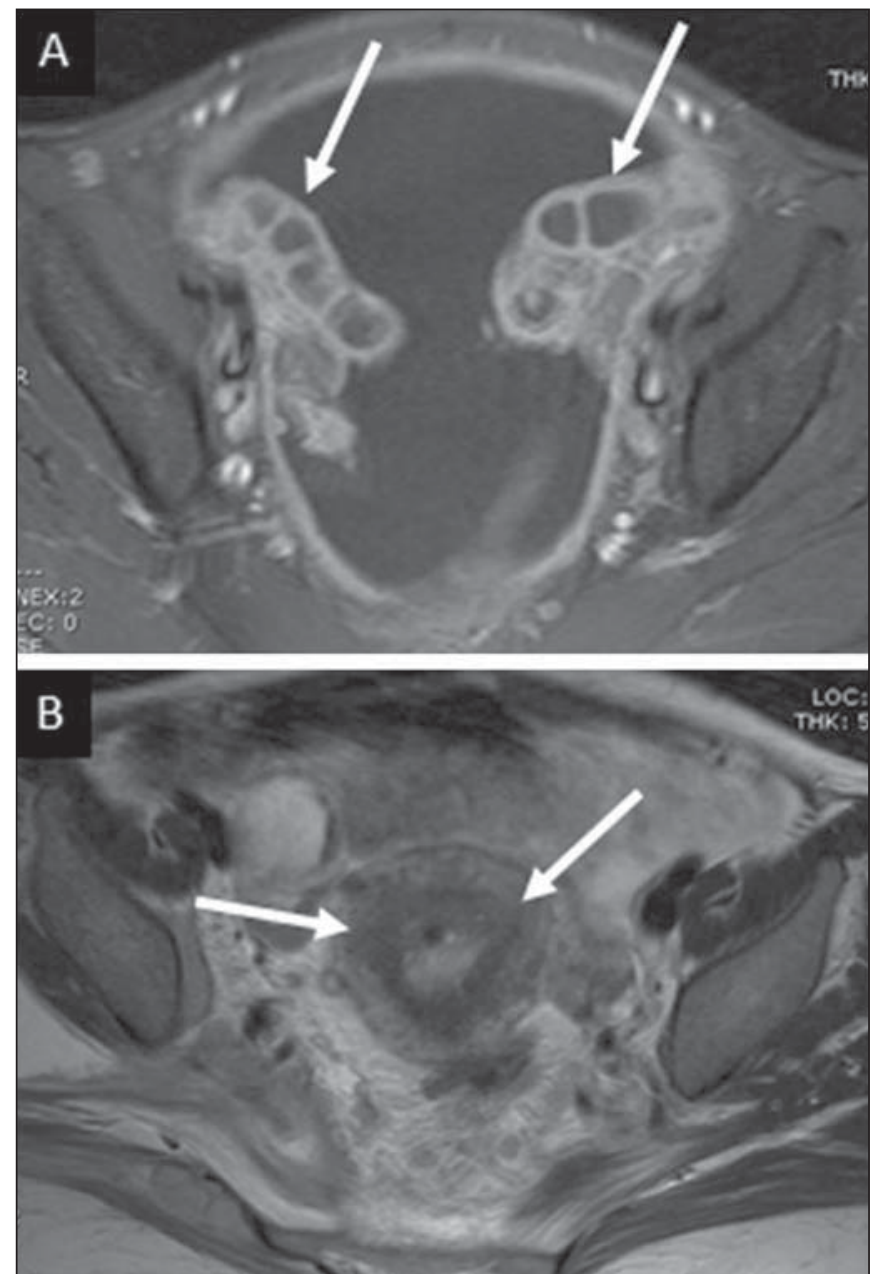

Figure 18. A: Adnexal tuberculosis. MRI shows diffuse parietal thickening with marked contrast uptake and dilatation of both uterine tubes at T1-weighted sequence with fat-suppression after intravenous contrast injection. B: Uterine tuberculosis. Axial MRI T2-weighted image demonstrates diffuse thickening of the endometrium and junctional zone (arrows), besides heterogeneous endometrial content. 
canalicular dissemination to the seminal vesicles, deferent ducts and epididymides. It may be either associated with renal lesions or present as an isolated condition ${ }^{(31)}$.

Epididymides are involved in 10-55\% men with urogenital tuberculosis ${ }^{(31)}$. Generally, it starts at the epididymal tail and later may propagate to the entire structure ${ }^{(26)}$. Sonographic findings include edema and heterogeneous echotexture of the involved segment. At MRI, increased volume and low signal intensity are observed at T2-weighted sequences, suggesting chronic inflammation and fibrosis ${ }^{(11,26)}$.

The seminal vesicles and deferent ducts may present wall thickening, stricture, and parietal or intraluminal calcifications at sectional images ${ }^{(26)}$.

Tuberculous prostatitis is characterized by decreased echogenicity and increased vascularization at Doppler ultrasonography, similarly to prostate cancer ${ }^{(12)}$. In patients with prostatic abscess (Figure 19), CT scans and MRI reveal cystic lesion with peripheral enhancement, indistinguishable from other causes of abscess. Dystrophic and nonspecific calcifications may be observed in the chronic phase of the disease ${ }^{(26)}$.

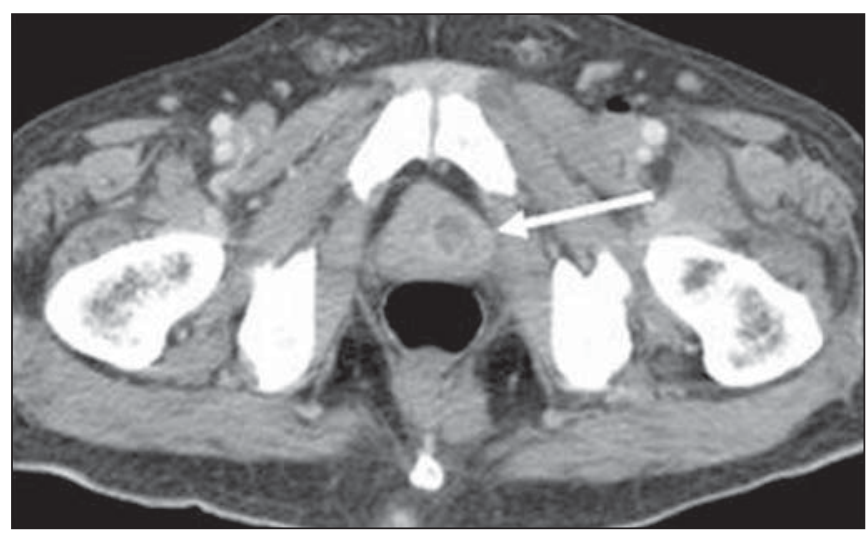

Figure 19. Prostatic tuberculosis. Hypoattenuating nodular lesion with peripheral enhancement compatible with abscess.

\section{OTHERS}

Iliopsoas muscle abscess (Figure 20) was a well known complication of vertebral tuberculosis until the implementation of modern chemotherapy schemes ${ }^{(32)}$. It may be classified into primary $(30 \%)$ or secondary $(70 \%)$, depending on the presence of an underlying disease, such as, tuberculosis. In developing countries, vertebral tuberculosis (Pott's disease) is considered to be the most common cause of psoas muscle abscess; however, few reports are found in the literature about psoas muscle abscess as a primary presentation of tuberculosis ${ }^{(33)}$. The presence of calcification in the abscess is virtually pathognomonic of tuberculosis ${ }^{(12)}$.

\section{CONCLUSION}

Tuberculosis presents a wide spectrum of clinical and imaging findings, and may affect many different organs in different ways. The diagnosis requires a high degree of suspicion and, despite the fact of being defined only by means of biopsy and specimens culture, it is important that the

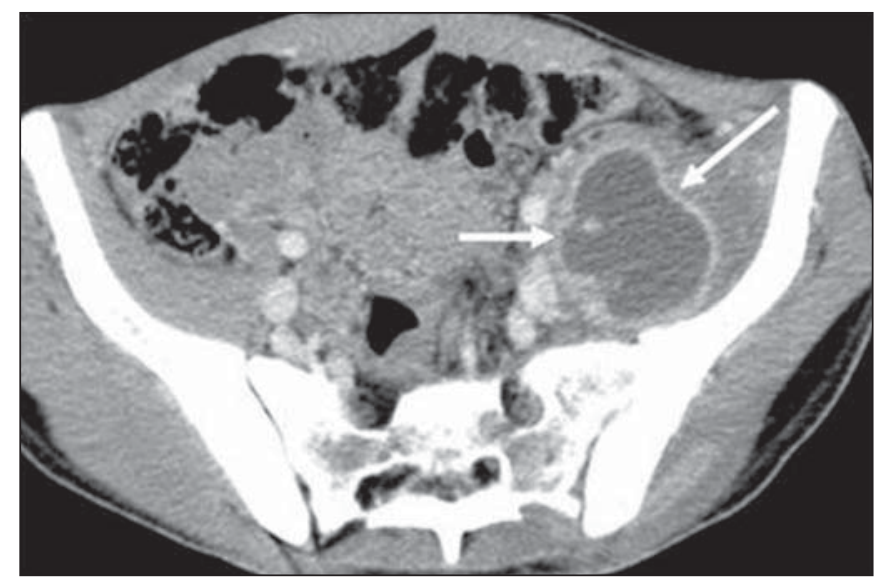

Figure 20. Iliopsoas muscle abscess. CT shows voluminous fluid collection with ring-shaped enhancement and thick capsule (arrows)

radiologist recognizes the imaging findings, allowing for the establishment of a more effective strategy to confirm the diagnosis and to institute the appropriate treatment as soon as possible.

\section{REFERENCES}

1. Lawn SD, Zumla AI. Tuberculosis. Lancet. 2011;378:57-72.

2. Aston NO. Abdominal tuberculosis. World J Surg. 1997;21:492-9.

3. Kapoor VK. Abdominal tuberculosis. Postgrad Med J. 1998;74:459_ 67.

4. Saluja SS, Ray S, Pal S, et al. Hepatobiliary and pancreatic tuberculosis: a two decade experience. BMC Surg. 2007;7:10.

5. Xu XF, Yu RS, Qiu LL, et al. Gallbladder tuberculosis: CT findings with histopathologic correlation. Korean J Radiol. 2011;12:196202.

6. Peixoto Filho AAA, Peixoto M, D'Ippolito G. Tuberculose peritoneal: como diagnosticar? Rev Imagem. 2007;29:47-52.

7. Gulati MS, Sarma D, Paul SB. CT appearances in abdominal tuberculosis. A pictorial essay. Clin Imaging. 1999;23:51-9.

8. Sinan T, Sheikh M, Ramadan S, et al. CT features in abdominal tuberculosis: 20 years experience. BMC Med Imaging. 2002;2:3.

9. Burrill J, Williams CJ, Bain G, et al. Tuberculosis: a radiologic review. Radiographics. 2007;27:1255-73.

10. Epstein BM, Mann JH. CT of abdominal tuberculosis. AJR Am J Roentgenol. 1982;139:861-6.

11. Harisinghani MG, McLoud TC, Shepard JA, et al. Tuberculosis from head to toe. Radiographics. 2000;20:449-70.

12. Engin G, Acunas B, Acunas G, et al. Imaging of extrapulmonary tuberculosis. Radiographics. 2000;20:471-88.

13. Suri S, Gupta S, Suri R. Computed tomography in abdominal tuberculosis. Br J Radiol. 1999;72:92-8.

14. Na-ChiangMai W, Pojchamarnwiputh S, Lertprasertsuke $N$, et al. CT findings of tuberculous peritonitis. Singapore Med J. 2008;49: 488-91.

15. Ha HK, Jung JI, Lee MS, et al. CT differentiation of tuberculous peritonitis and peritoneal carcinomatosis. AJR Am J Roentgenol. 1996;167:743-8.

16. Pereira JM, Madureira AJ, Vieira A, et al. Abdominal tuberculosis: imaging features. Eur J Radiol. 2005;55:173-80.

17. De Backer AI, Mortelé KJ, De Keulenaer BL, et al. CT and MR imaging of gastrointestinal tuberculosis. JBR-BTR. 2006;89:190-4.

18. Nagi B, Kochhar R, Bhasin DK, et al. Colorectal tuberculosis. Eur Radiol. 2003;13:1907-12.

19. Sharma MP, Bhatia V. Abdominal tuberculosis. Indian J Med Res. 2004;120:305-15. 
20. Nagi B, Lal A, Kochhar R, et al. Perforations and fistulae in gastrointestinal tuberculosis. Acta Radiol. 2002;43:501-6.

21. Chong VH, Lim KS. Hepatobiliary tuberculosis. Singapore Med J 2010;51:744-51

22. Chong VH. Hepatobiliary tuberculosis: a review of presentations and outcomes. South Med J. 2008;101:356-61.

23. Kumar K, Ayub M, Kumar M, et al. Tuberculosis of the gallbladder. HPB Surg. 2000;11:401-4.

24. De Backer AI, Vanhoenacker FM, Mortelé KJ, et al. MRI features of focal splenic lesions in patients with disseminated tuberculosis. AJR Am J Roentgenol. 2006;186:1097-102.

25. Nagar AM, Raut AA, Morani AC, et al. Pancreatic tuberculosis: a clinical and imaging review of 32 cases. J Comput Assist Tomogr. 2009;33:136-41.

26. Jung YY, Kim JK, Cho KS. Genitourinary tuberculosis: comprehensive cross-sectional imaging. AJR Am J Roentgenol. 2005;184: $143-50$.
27. Mayo-Smith WW, Boland GW, Noto RB, et al. State-of-the-art adrenal imaging. Radiographics. 2001;21:995-1012.

28. Muttarak M, ChiangMai WN, Lojanapiwat B. Tuberculosis of the genitourinary tract: imaging features with pathological correlation. Singapore Med J. 2005;46:568-74.

29. Ghosh K, Ghosh K, Chowdhury JR. Tuberculosis and female reproductive health. J Postgrad Med. 2011;57:307-13.

30. Chavhan GB, Hira P, Rathod K, et al. Female genital tuberculosis: hysterosalpingographic appearances. Br J Radiol. 2004;77:164-9.

31. Figueiredo AA, Lucon AM. Urogenital tuberculosis: update and review of 8961 cases from the world literature. Rev Urol. 2008; 10 : 207-17.

32. Mallick IH, Thoufeeq MH, Rajendran TP. Iliopsoas abscesses. Postgrad Med J. 2004;80:459-62.

33. Chawla K, D'Souza A, N SB, et al. Primary tubercular psoas abscess: a rare presentation. J Infect Dev Ctries. 2012;6:86-8. 